\title{
6. Backpack reporting of Typhoon Haiyan in the Philippines Implications of convergent technologies on disaster journalism
}

\begin{abstract}
This article offers an analysis of digital technologies' implications on disaster reporting using the perspective of a journalism-documentary practitioner. The study uses Typhoon Haiyan disaster as a case study and is based on an ethnographic analysis of the author's backpack news production in post-disaster regions in the Philippines. It supports the notion that media convergence adds valuable new elements to storytelling and presentation of news but it only refines and not replaces traditional newsgathering methodologies. Drawing on the theories of emotional discourses in disaster reporting (Pantti, Wahl-Jorgensen \& Cottle, 2012), media convergence and technological determinism, this article argues that journalists practising the backpack-style are confronted with more technical issues and even higher stress-level working in disaster zones, but being solo provides more opportunities to practise humanistic storytelling. Backpack journalists immersing in disaster zones can collect more personal narratives from survivors of a disaster who feel less intimidated by their use of informal equipment.
\end{abstract}

Keywords: backpack journalism, disaster reporting, human rights journalism, multimedia, Philippines, storytelling, technological convergence, Typhoon Haiyan

NORMAN ZAFRA

University of Auckland

\section{Introduction}

-his research is interested in the relationship between multiskilling in news media and its impact on disaster reporting. It draws upon the notion that news routines are evolving as a way to adapt to the emerging technologies that are available for news workers and to enrich the content of journalism (Pavlik, 2000). In particular, the typhoon disaster coverage presented 
here is focused primarily on online text production and the convergence of media outputs (text, video, audio and interactive graphics) in ubiquitous internet platforms. In the beginning, convergence in journalism refers primarily to the practice of integrating newsrooms owned by a parent company. But the term has metamorphosed and has undergone major redefinition over the years (Kolodzy, Grant, De Mars, \& Wilkinson, 2014; Stevens, 2002). Today, the term 'converged journalism' does not necessarily indicate that journalists occupy the same space under the same roof in order to produce multimedia stories. Mono-media organisations composed of multiskilled or backpack journalists producing multimedia contents are also practising the new convergence. As a matter of fact, it is cited that the concepts 'convergence' and 'multimedia' are to a great extent synonymous (Infotendencias Group, 2012, p. 25). Journalism has indeed entered a new era of convergence - the turn to the digital, the interactive and the multimedia type of storytelling and the independent, multiskilled and technology-empowered backpack news production. But how does the new style of reporting using convergent technologies modify the workflow patterns of journalists covering natural disasters? And with the increasing number of climate-related disasters worldwide, is backpack style-journalism a good alternative? Can it produce better narratives?

\section{Disaster overview}

The Typhoon Haiyan disaster (also called Yolanda) that devastated mostly the central regions in the Philippines provides a distinct case study that demonstrates the impact of technologies on work routines of journalists in disaster zones. Unlike the daily grind of journalism, natural disasters pose greater challenges to journalists due to limitations in terms of infrastructure that makes information less accessible. The typhoon disaster that took place in November 2013 is arguably one of the most highly covered events in the Philippines by local and international media. In fact, many innovations in news reporting have been exercised in the reportage of Haiyan from flying unmanned aerial vehicles or drones that captured a bird's eye view of the devastation to exercising interactivity in news presentation (Strong \& Zafra, 2016). Typhoon Haiyan showcased the ever typical impact of disasters to developing nations: the consequences on human health including death tolls and physical injuries, the consequences on agriculture and livelihood, and the consequences on settlement and housing (Alexander, 1993). Government data revealed that Typhoon Haiyan killed 6,300 individuals and caused overwhelming damage to infrastructure and agriculture. Haiyan also displaced four million Filipinos and forced more than 100,000 people to live in evacuation centres (UNOCHA, 2013; NDRRMC, 2013). These issues have been reported extensively by the media that covered the disaster. While the presence of local and international media covering the 
disaster contributed largely to generous aid funding from foreign governments and organisations, it nonetheless fuelled media fatigue among survivors who were continuously asked repetitive questions about their experience. The wrath of the disaster, the scale of the devastation and the participation of journalists in constituting the narratives of the survivors made this even more promising as a case study on journalistic practices.

\section{Media convergence: Definition and historical background}

While it is true that many researchers have a general understanding of the meaning and implications of media convergence, it is still an ambiguous term even two decades after it was first introduced. Scholars and media practitioners argue that a single definition does not matter and may be difficult to achieve because convergence is defined by the "media market place, and the marketplace conditions are different from one location to another' (Quinn, 2005, p. 8). A popular and common notion of the term is the blurring of boundaries between and among different media and communication platforms (Quandt \& Singer, 2009). Media convergence has been defined in a number of ways such as: 'The combination of technologies, products, staff and geography among the previously distinct provinces of print, television and online media' (Singer, 2004, p. 286); the cooperation between print and broadcast media for the delivery of multimedia content through the use of computers and the internet (Lawson-Borders, 2006); and the modified storytelling strategies and techniques of the formerly considered medium-specific platforms (Zelizer \& Allan, 2010). In the past, a newspaper company produced content solely for print publication and a television network was limited only to its broadcast outlet. But in the 21 st century journalism, boundaries between media channels are blurred and journalists are increasingly expected and required to produce multimedia content and deliver news across platforms.

The origin of the word convergence as applied to communication industries has been a point of debate among media researchers. Many scholars, however, cite Ithiel de Sola Pool's popular 1983 book, Technologies of Freedom, as a proof of early discussions on convergence (Gordon, 2003). Pool, who was later referred to as the prophet of media convergence by media scholar Henry Jenkins (2006), was credited as one of the first authors who wrote on the concept of convergence of modes.

A process called the 'convergence of modes' is blurring the lines between media, even between point-to-point communications, such as the post, telephone and telegraph, and mass communications, such as the press, radio, and television. A single physical means - be it wires, cables or airwaves - may carry services that in the past were provided in separate ways (Pool, 1983, p. 23). 
The practice of convergence began in the mid-1990s when companies around the world started some forms of cross-media synergy and interaction (Deuze, 2007). An example was a partnership between a television station and a newspaper owned by at least two separate companies. The convergence here was a form of business arrangement, in which one media cross promotes another (Quinn, 2005a). Although earlier discourses on convergence associated the term as a dangerous word due to its perceived nature as inevitable and necessary (Silverstone, 1995), the media industry was quick to embrace convergence, albeit using different styles. But there was no single model of convergence among media organisations. Convergence journalism took place in a 'variety of newsrooms, in a variety of manners' (Kolodzy, 2006, p. 10). Thus, there is no absolute template to implement convergence in journalism since different cultures, companies and countries may exercise diverse forms and layers of convergence (Boczkowski \& Ferris, 2005; Quinn, 2005).

What has been labelled as full convergence in its early days is the physical movement of news outlets, owned by the same company, into a single roof that enabled efficient news production across platforms. This convergence model has drawn several academic studies focusing on the changes happening within fully combined newsrooms. Two major strands of research emerged (Erdal, 2009). The first is the organisationally-oriented branch concerned in analysing how convergence introduces changes in the organisational structures and routines of the newsrooms (e.g. Zhang, 2012; Erdal, 2009; Dupagne \& Garrison, 2006; Klinenberg, 2005; Bhuiyan, 2009; Singer, 2004; Duhe, Mortimer \& Chow, 2004; Larrondo, Larrañaga, Meso, \& Agirreazkuenaga, 2012). Examples of these converged newsrooms are multimedia desks in Tampa headquarters in Florida and the World Company in Kansas, USA (Colon, 2000; Gage, 2006), Turun Sanomat Group in Finland, NordJyske in Denmark, Ming Pao Group in Hong Kong, and the Guardian Media Group in the United Kingdom (Quinn, 2005). In the convergence continuum model of Dailey, Demo and Spillman (2005), these examples are classified as fully converged newsrooms wherein partners cooperate not only in the newsgathering stage but also in the dissemination of news. The second research strand, on the other hand, examines the impact of digital communication technologies on the individual routines and practices of multiskilled journalists (e.g. Robinson, 2011; Huang, Rademakers, Fayemiwo \& Dunlap, 2004; Pavlik, 2000; Wallace, 2013; Reich, 2011).

\section{Multiskilling and technological convergence}

There has always been a constant effort, among news managers, to routinise journalism work given the perception that it helps 'control the flow of work' (Tuchman, 1973, p. 110). Technology is a particular element of this routinisation. Research on new media and journalist routines, however, is still a young 
but fast emerging field of scholarly inquiry. Ethnographic studies have been the common research approach, together with cross-media content analysis and in-depth interviews (Quandt \& Singer, 2009). Most scholarship in this field argues that 'technological developments generate editorial effects' (Boczkowski, 2004 , p. 207) and that content is transformed due to technological changes (Pavlik, 2000). Rather than studying the physical convergence of newsrooms, this production-focused paradigm explores the online and multimedia adaptation of news organisations, such as using the web as a news platform and training journalists to become multiskilled workers.

Multiskilling can be subdivided into three categories: a media multiskilled journalist capable of filing news reports for multiple media; a technical multiskilled journalist performing technical duties on top of traditional reporting functions; and an issue multiskilled journalist similar to a general assignment reporter (Domingo et al., 2011). It is argued that companies adopt multiskilling mostly to improve cost-effectiveness, to reorganise the newsroom and as a convenient excuse for job cuts (Avilés, León, Sanders \& Harrison, 2004; LeeWright \& Phillips, 2012).

Furthermore, use of multiskilling backpack journalists most often working alone provides an advantage to newsrooms who have fewer staff (Kumar, 2011) although at the 'price of newsroom collaboration and camaraderie' (Bock, 2012, p. 33). For instance, photojournalists are now being trained to record videos and are also expected to be proficient in digital software in order to produce multimedia contents (Wesley, 2013). Because backpack journalists perform both technical and reportorial jobs, they are referred to as the embodiment of convergence (Boczkowksi, 2004a; Deuze, 2004).

Although multiskilling is highly advantageous among multimedia news organisations, others are sceptical. Converged journalists working for BBC regional newsrooms assert that multiskilling can lead to higher stress levels for news workers (Wallace, 2013). Other studies have highlighted the negative perception of multiskilling such as the increased work pressure for journalists, specialists reassigned as generalist reporters and criticisms that it provides less value for news workers (Deuze, 2008). Consequently, it should be seen as a refinement of an existing method only and not a replacement of established news gathering practices (Kennedy, 2010).

Multiskilled journalists also called 'one-man-band' and 'Inspector Gadgets' (Quinn, 2005) long existed in documentary filmmaking with young reporters from smaller markets shooting, writing and editing their film with the goal of eventually landing a career in bigger markets (Bock, 2012). The so-called 'single-authored news production' also gained greater acceptance in recent years and was institutionalised as a practice in traditional newsrooms. In television, the practice is credited to the personal digital production experiment 
of Michael Rosenblum, a former CBS news producer turned media consultant who conducted multiskill training for journalists at the BBC (Hemmingway, 2005; 2008, p. 79). Rosenblum's model of 'single-authored-news production' is similar to the concept of backpack journalism wherein the demarcated roles within the news production that blurred previous boundaries were assumed by a single person (Hemmingway, 2008). Since then, this practice is referred to in various terminologies such as video journalists, MOJO or mobile journalists, multimedia journalists, OMBs or one-man bands, Do Platypus, SoJo or solo journalists and APJ or all platform journalists (Martyn, 2009; Tompkins, 2012; Smith, 2011). Despite being perceived as 'jack of all trades and master of none' (Huang et al. 2006), backpack journalists are still often deployed to cover war and disaster zones.

\section{Methodology}

The findings of this research are based on an ethnographic case study of the author's backpack news production in post-disaster regions in the Philippines. The choice of ethnographic methodology was based on the desire to provide a rich and reflective description of the process of backpack reporting including the context of its application. The production took place in September 2014, ten months after the disaster, and for a period of one week including inland travels. The author's fieldwork covered two post-disaster communities in Central Philippines: Tacloban, the city that suffered more than 2000 deaths due to storm surge and had the worst damage to infrastructure, and the coastal town of Guiuan, where the typhoon made its first landfall. The investigative story produced by the author talked about the status of recovery of the Philippines after the disaster and probed why, despite the billions of dollars of aid funding from various sources, recovery remained slow. The story produced for this research pinpointed the controversial and complex issue of land tenure in the Philippines that hindered the relocation planning of the government and forced the vulnerable population to return to no-build zones.

The data derived from the author's field work, observation and interviews were analysed using the theories of emotional discourses in disaster reporting (Pantti, Wahl-Jorgensen \& Cottle, 2012), media convergence and technological deterministic framework. Practitioners in particular use technological determinism in explaining the changes in their work because technology is a visible and tangible component of their routines and also because of the deep historical roots to examinations of the relationship between technology and reporting (Örnebring, 2010).

\section{Discussion}

Backpack journalism in disaster zones

The capacity of one person to multiskill is primarily driven, if not determined, 
by technological developments. The popularity of the so-called 'one-man bands' capable of producing multimedia content is also made possible by the availability and affordability of new technologies. Nowadays, digital journalists are required not only to think creatively, visually and narratively from newsgathering to presentation, but also to 'think technically' (Bock, 2012, p.5). To illustrate the impact of digital and lightweight equipment on my field work in post-disaster regions in the Philippines, it is important to distinguish backpack from reporting with a news crew. A news crew, if not broadcasting live from the field, typically consists of TV presenter and/or producer, a videographer and an assistant videographer. The number of crew members may be slightly higher depending on the type of story or whether it is local or international coverage. Conventional and convergent technologies often differ from each other in terms of the complexity of equipment and accessories used in field work, the degree of preparation prior to filming and the amount of time needed to pack up after each coverage. My routine in documentary journalism, for instance, means carrying bulky cameras (often two-camera set up), professional tripods, three-point lighting kit, complex audio equipment such as clip-on and shotgun microphones, and other essentials such as memory cards, extra batteries, charger, lenses, cables and other accessories. Even in covering natural disasters, television crew still carry the same basic set of equipment, but prefer portable rather than complex lighting gear. My backpack reporting toolkit used in the Philippines was simplified and was reduced to the most essential:

- a DSLR (digital single-lens reflex) camera with an $18-55 \mathrm{~mm}$ lens capable of taking quality photographs and full high-definition videos

- a mini personal tripod to create professional looking moving and still images

- lavalier or wireless lapel microphone as a primary audio device

- smartphone as back-up audio and video recording

- earphone

- charger, memory cards, extra batteries

- computer installed with photo and editing software

- notebook and pen

An important consideration for me during my coverage was the selection of the equipment to use in the Philippines. Because I knew very well (from preliminary research) what stories to cover, interviews to conduct and places to visit; it worked to think backward and determine ahead what equipment would be necessary for my news production. I reiterate that the list I provided above is not a textbook-based backpack reporting toolkit but rather a product of both my production knowledge and anticipation of the environment that I will cover. 
I considered several issues such as the length of international travel from New Zealand to the Philippines, domestic travels within my destination country and the availability of public transport in the field.

These pieces of gadgetry had a huge impact on my own backpack journalism routine. Social immersion, for instance, was more feasible with lightweight equipment. Even my choice of using a personal and mini tripod instead of a bigger-although-steadier one, was proven advantageous in many instances such as practically carrying less weight when travelling and blending with the crowd when filming in public places. My coverage of two places in the Philippines, the coastal town of Guiuan and the city of Tacloban, was smoothly completed partly because of the portability of my newsgathering tools. More importantly, I gained local insights and backstories while taking public transport from one place to another, which added value to my knowledge production. Observations made while being solo provided greater depth and nuance particularly to my long-form article, which I chose to present using first person narrative technique. Due to this, it is easy to conclude that my immersion in post-disaster communities gave me the advantage of being an insider that made my reporting upfront and credible. I highlight that the core of backpack journalism's convergent toolkit is the digital camera-an extension of the reporter's mind and body that facilitates the dual purpose of truthseeking and engagement at the same time. Similar to Creech's (2017) analysis of camera as mode of truth production, my lightweight digital camera granted me affordances that turned my visuals more granular and contextual.

Because I was doing the field work alone, I also enjoyed the liberty of deciding merely for myself and not for a news crew. Hence, I exercised a unique layer of independence different from my earlier experience as a journalist. I concur with Wallace (2009) that backpack journalists are able to exercise creativity and greater control of news production. More importantly, small equipment was unobtrusive and did not attract attention from the crowd. This notion reminded me of how veteran journalist Cyndy Green highlighted 'the cloak of invisibility' in backpack journalism (cited in Kennedy, 2010, p. 3). In comparison with big cameras that attract attention when filming in public places, the use of smaller equipment does the contrary. As Tompkins (2012) has argued, there is the benefit of blending with the crowd using a small consumer-sized camera. These experiences confirmed that 'one-man-band' reporting was not only cost-effective but also a flexible option for news coverage (see Avilés et al., 2004).

\section{Obstacles in solo disaster journalism}

Although I have illuminated the advantages of being solo in disaster zones, it is equally important to note that it should be seen as a refinement of an existing method only and not a replacement of established newsgathering practices (Kennedy, 2010). First, backpack journalists are faced with serious technical issues and 
limitations in the field and even greater when in disaster zones. For instance, not all existing camera brands allow the user to monitor the audio while it is being captured. While interviewing the vice mayor of Tacloban, the lavalier microphone failed to record audio due to poor batteries. These technical problems are less likely to happen with a crew that looks after the technical side of production. I agree that the mechanical errors add another layer of work for a backpack journalist such as syncing the audio and the video interview during post-production. A back-up audio recorder (e.g. smartphone) is desirable when conducting sit-down interviews, which is also an efficient device to review the interviews during spare time such as in between long travels. As cautioned by Avilés et al. (2004), multiskilling leaves less time for traditional journalistic practices such as cross-checking of sources and finding contextual information. When reporting disaster as breaking news, these technical issues also disturb the supposed speed of converged journalism.

Second, the loaded tasks shouldered by the backpack journalist demand more attention to technology rather than content. While news managers usually require multitasking and not multiskilling as criteria for retention, both of them are frequently demanded (Lee-Wright \& Phillips, 2012). Multitasking-completing multiple tasks at a time-involves a number of technical jobs such as setting up the tripod, framing interview background, connecting cables and wires, audio-video recording, getting proper exposure and focus, audio monitoring, as well as stopping the recording momentarily to avoid overheating. Regardless of prior training in production, my backpack reporting experience in the Philippines demonstrated that multitasking adds to increased work pressure (Deuze, 2008), leads to higher stress levels among journalists (Wallace, 2013) and may also compromise precision in journalism (see Meyer, 1973). It can be argued that increasing the depth and accuracy of news is far more demanding in disaster reporting wherein stories unfold faster and access to official sources is more difficult. And with the focus on technology, the capacity of the journalist to conduct deeper investigation or ask difficult questions is consequently reduced (Wallace, 2009). I also needed to remind myself that I was dealing with sensitive and vulnerable subjects who lost their loved ones during the typhoon and needed to be treated gently. Apart from that, I was also working in a physically difficult terrain with less tourist infrastructure.

And third, being independent is liberating but it is a big departure from the group dynamism and supposed 'multifacetedness' of news production. It is possible that a news organisation would deploy a backpack journalist to cover a disaster story because it is a more efficient, cost-saving and flexible option nowadays (Avilés et al., 2004). However, as Bock (2012) argues, this decision is done at the expense of newsroom collaboration and camaraderie. This means that backpack reporting, although it saves time and money, requires longer working 
hours for journalists. My experience shows that although backpack journalism gives me the flexibility to work independently, the probability that a journalist would produce a more comprehensive report given a limited time is higher when working with a crew. In this case, I highly suggest assigning backpack journalists to feature stories to be able to work with ample preparation. However, they are also ideal to be assigned to cover breaking disaster stories but working in tandem is more efficient.

\section{Multimedia as the centre of backpack reporting}

Historical assessments reveal how technology changes the nature of news content. One interesting transformation is how the 'immersive and interactive multimedia news reports' on the web are supplanting the once-basic inverted pyramid news (Pavlik, 2000, p. 232). Converged technologies allow the simultaneous creation of multiple media for online distribution and also offer a new style of narrative journalism.

The outputs of my backpack reporting are comprised of the following: a short news documentary about the Philippines' post-disaster recovery, still photos, a long-form feature article and several interactive contents (see Figures 1-3). The article uses the first-person narrative style, an emerging form of contemporary multimedia journalism. Because disaster events merit contextual journalism, innovations should also be exploited by backpack journalists. For instance, the huge volume of data such as the aid contributions from foreign governments was transformed into an interactive story map (Figure 2). It shows 64 donor countries that contributed in rebuilding the Philippines, and is comprised of 128 data entries stored and layered on top of the Google base map (Google Maps Engine API, 2014). Each clickable content bears a photo of the country's flag for better visualisation. The process, which took several hours to complete, involved collating and assigning data for each country using Google Maps and then individually drawing a yellow curved line to illustrate the sources of funds. It is effective in illustrating the power of the web to hold and showcase complex a volume of information. As Lewis and Westlund (2014, p. 450) noted: 'Data - whether "big" in the sense of being too complex for traditional database management software, or simply "big" in its potentially transformative import - has taken on particular relevance for news'.

Instead of merely presenting the chronology of key events after the disaster as a rundown of dates, my audience was given the power to interact with the story through a timeline. The Timeline JS was used to convert a modest list of typhoon-related events into a non-linear and interactive story (Figure 3). It is an open-source tool that offers journalists an easy way to create a visually-rich and interactive chronology of key dates (Timeline JS overview, 2014). It reminded the audience about the news that they might have missed after the international 


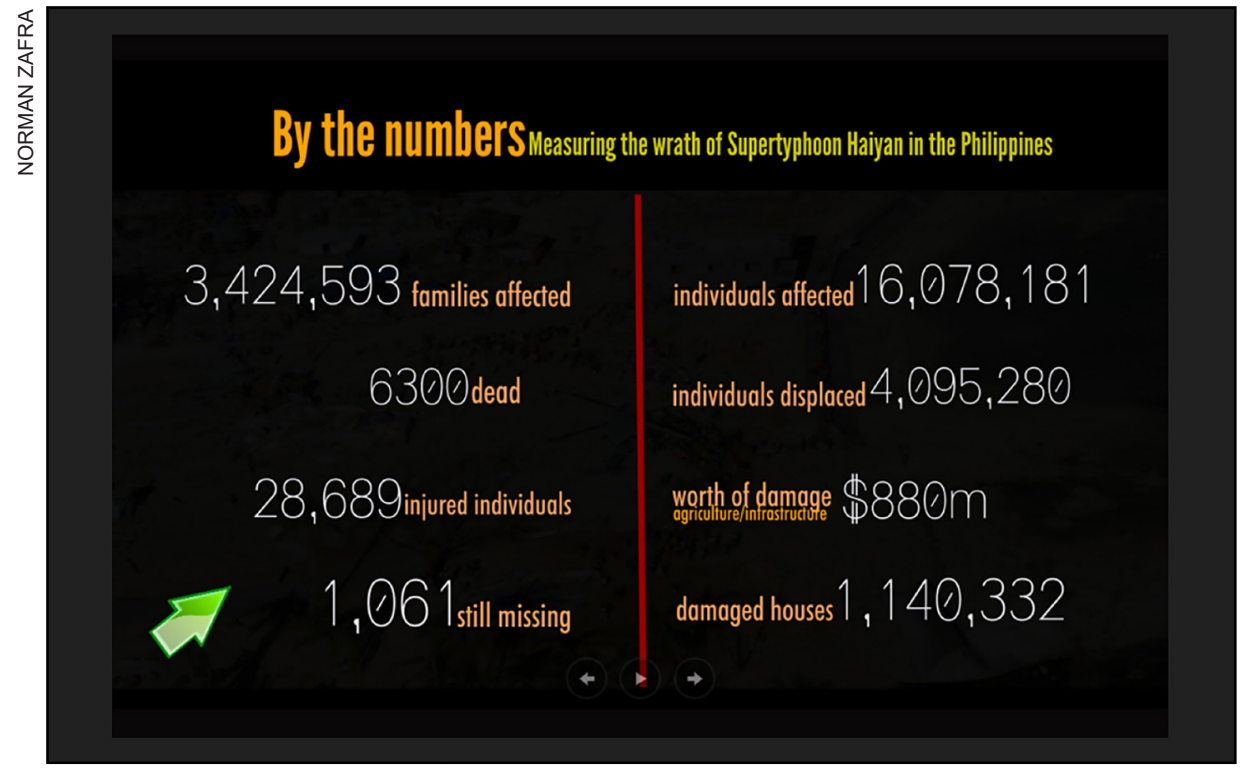

Figure 1. The disaster in context, infographics in slideshow format

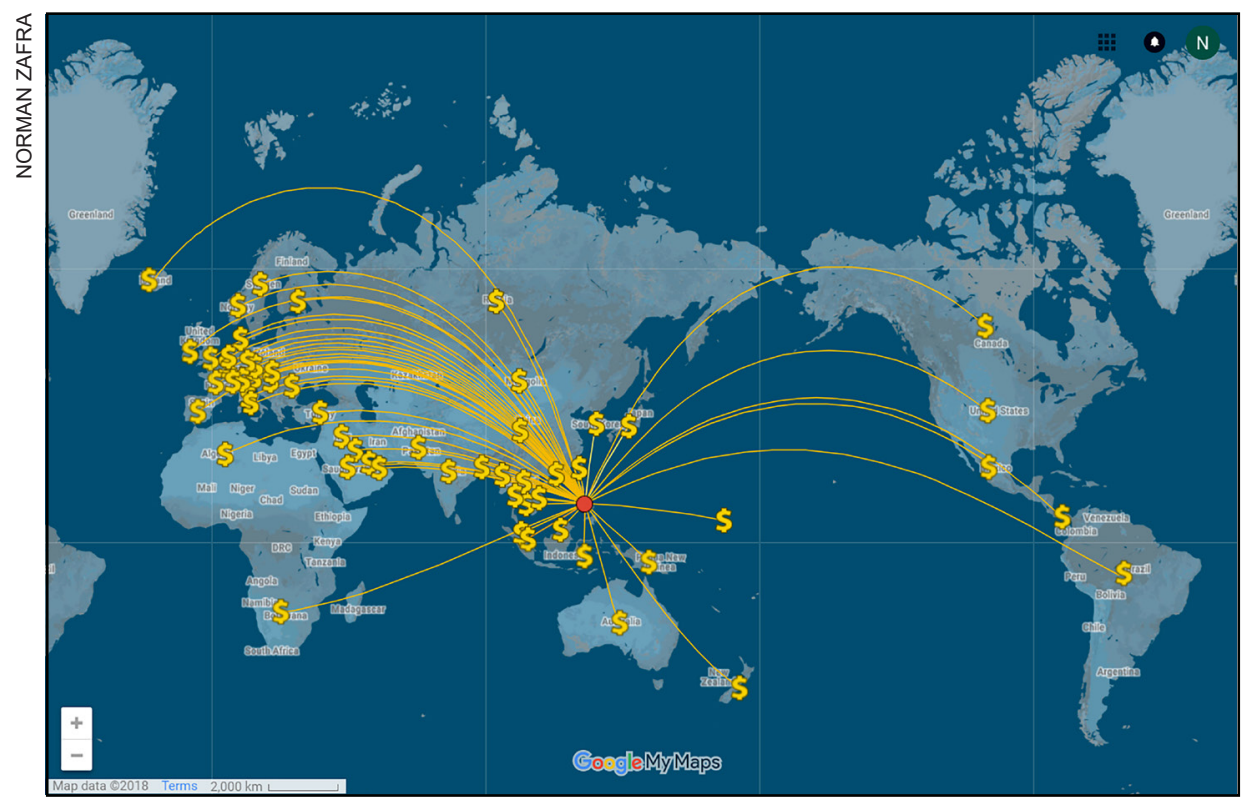

Figure 2. Interactive map showing sources of foreign aid for Typhoon Haiyan survivors in the Philippines (in US dollars). Data provided by gov.ph/faith.

media hype on Typhoon Haiyan. Instead of putting the data as a text or graphics, the interactive timeline offered greater engagement with the readers. Google Spreadsheet (similar to an Excel document) is required in setting up a timeline. 


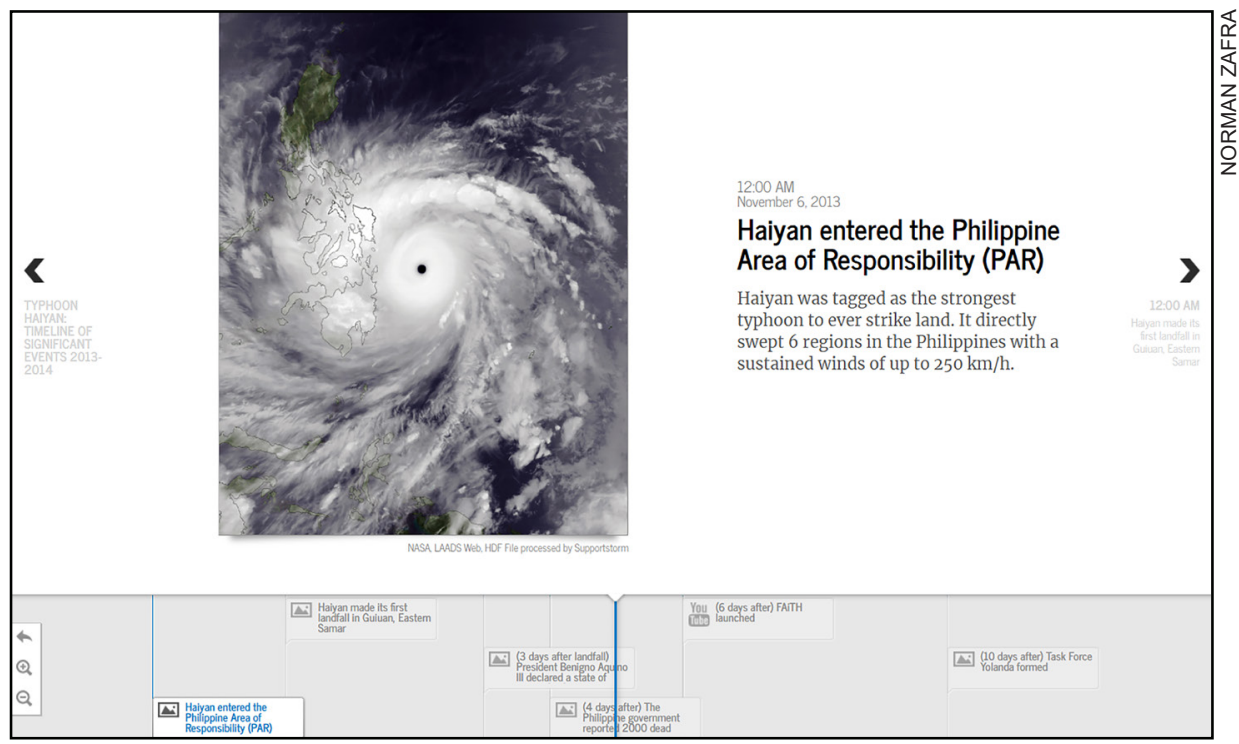

Figure 3. Screenshot of interactive timeline created using Timeline JS

All applications, software and online tools that I used to create these interactive media are publicly available which means journalists are given enough resources to enhance the content of their disaster reporting.

Before the prevalence of web and convergent technologies, journalists were practising medium-specific storytelling, with each platform using a 'set of sign systems' (Erdal, 2009, p. 178). Broadcast journalists report the news through video and audio while newspaper journalists use texts as their primary means of reportage. Historically, the production of multimedia news has been mainly attributed to the emergence of three new platforms: desktop computers, portable devices and interactive television (Gordon, 2003). These media offered the potential for unlimited space and time, immediate publishing, audience interaction, user content, multimedia content delivery options and user's greater control over content. The practice of repurposing or reproducing content (Erdal, 2009) for the web has grown exponentially over the years as a response to the migration of news consumers to digital platforms as well as the information-seeking attitude of the audience (Quinn, 2004). This has a significant impact on the mindset of a backpack journalist. The multimedia trend influences the journalist's desire to capture more media as much as possible, organise, and then decide which one is publishable after the coverage. However, multimedia is not necessarily the agent of this mindset. In Tuchman's 1973 article titled Making news by doing work: Routinizing the unexpected, she noted that journalists naturally choose to cover as many stories as possible. 
Such a practice is tempting, for the newsman wants to turn in as much copy as possible and this is accomplished more easily by skimming the surface of many stories than by digging down a potential 'blind alley' to provide intensive coverage of one event-as-news (Tuchman, 1973, p. 124)

Similarly, backpack journalists may be inclined to overshoot and rely on the capacity of the camera to take endless media, or in the words of Lee-Wright and Phillips (2012, p. 69) - shifting the "emphasis from newsgathering to output production". I argue that without enough experience and skills in editorial judgment, this attitude may compromise the depth of reporting.

\section{Humanising disaster narratives}

Stories about disasters are a magnet of attention in the journalism circle due to their dramatic, inspiring and heroic elements and yet also criticised due to the potential to focus on the demeaning stereotypical representations of the poor victims and less emphasis on important issues (Stewart \& Hodgkinson, 1988; Bennett \& Daniel, 2002). The duty of journalism during a disaster is clear. The high predictability of natural disasters, specifically typhoons, means that journalists perform a crucial role in the public constitution of a disaster including how it is communicated to and perceived by its audiences (Pantti, WahlJorgensen \& Cottle, 2012). Humanising its news presentation is a key element of disaster journalism as it brings to the public sphere a collection of emotions that the public can engage with. Emotional discourses in disaster journalism are also valued because of the capacity to push political actors to respond, to commit and to act with moral judgments during a crisis, and to stimulate interest and public understanding of the news (Pantti, Wahl-Jorgensen \& Cottle, 2012). Thus, the mediatisation of disasters is more than the act of representation as it also triggers 'collective empathy' and 'critical engagement' (Cottle, 2012 , p. 261). However, it is important to balance emotions in reporting to ensure that its 'affective and informational' objectives are achieved (p. 87). And while emotion may challenge the traditional view of journalism as impartial and objective, the presence of a disaster legitimises its use as a narrative element (Pantti, 2010). Journalists have been cautioned to use it proportionately, to test it against facts and to ensure that the story is the centre of the reporting and not the storyteller (Ward, 2010).

It is in this theoretical perspective of emotion and disaster that backpack style of reporting could be positioned as strategic. Although working alone poses a number of risks in the technical side of journalism, it is good to note its advantage in humanising disaster narratives. As a journalist using consumersized camera, the community showed more willingness to accept my invitation for interviews despite having no local guide to back up my credibility. Unlike my prior coverage of disaster in the Philippines wherein social workers or 


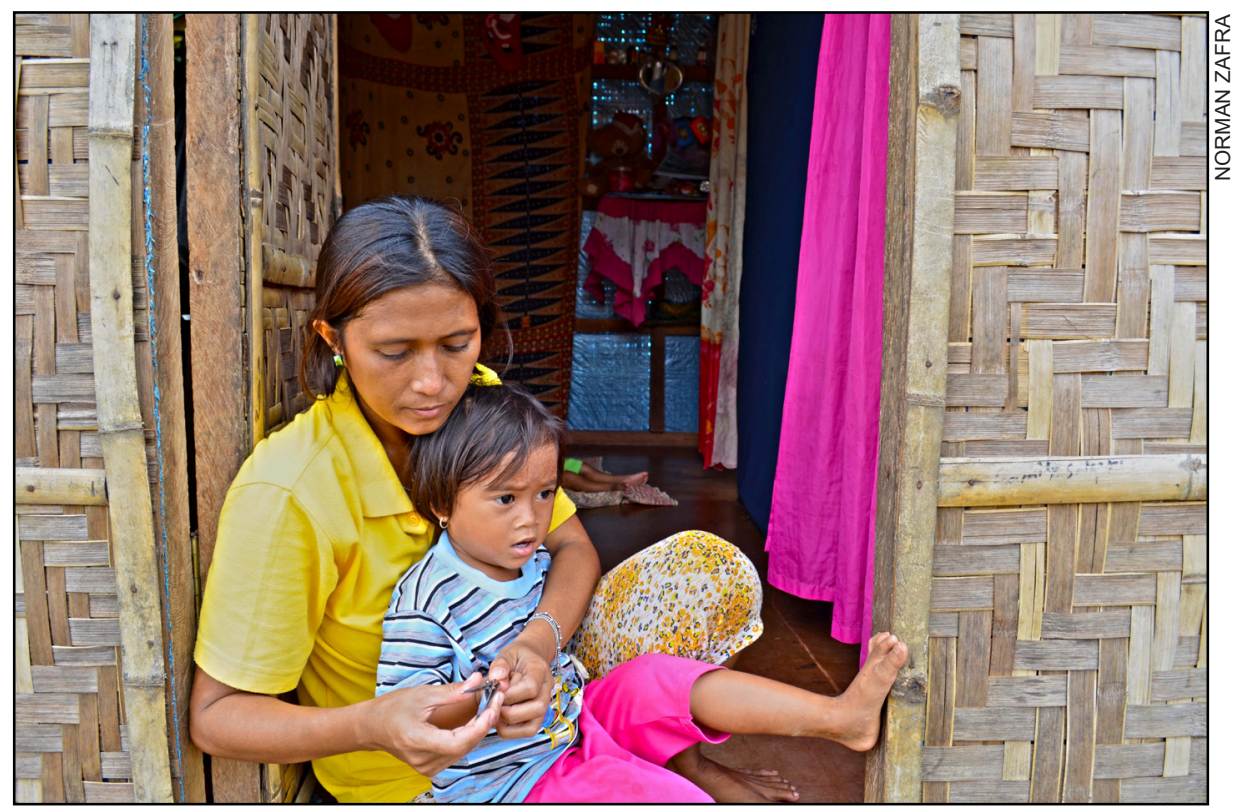

Figure 4. Typhoon survivor in Tacloban appeared natural in front of the camera and felt casual enough to clip her child's fingernails during the filming.

humanitarian NGO officers usually accompany the crew in the field, being solo is a liberating experience that allowed me to know the community deeper, including their issues that need more public awareness. Hence, I was able to bypass the gates of humanitarian non-profit organisations that usually stand as information providers and mediators between the journalist and the community (Van Leuven \& Joye, 2014).

When I visited the homes of my subjects in evacuation and transitional sites, I was treated as a guest rather than as news worker whose primary mission is to produce a story. Being solo, it was easy to create a feeling of familiarity among my interviewees who felt less intimidated by a DSLR than professional cameras used in mainstream television. One of the typhoon survivors featured in my documentary, told me that during the aftermath of the typhoon, some victims felt a fatigue to answer the same type of questions from media and disaster researchers (Personal communication, 3 September 2014). Reporting solo and using lightweight equipment, however, were advantageous in soliciting a fresh story angle, personal narratives and getting intimate with the subjects. As Lee-Wright and Phillips (2012) noted, there is a demand for personal anecdotes in journalism in order to engage with the audience. My experience in television revealed that the mere presence of a news documentary crew composed, for instance, of a director, a producer, a television host and a videographer, could overwhelm and intimidate disaster survivors, may alter the surroundings and could contribute 
to a person's tendency to appear tensed and unnatural in front of a camera. On the contrary, I was able to create a comfortable atmosphere during the sit-down interviews and banter with my subjects. In fact, my interview with a survivor in a transitional housing site in Tacloban City became more of a personal and free-flowing conversation rather than a rigid recorded interview. Before the interview, she offered me her home-made coconut candies and introduced me to her neighbours. Interestingly, while taking her b-roll shots, she felt casual enough to clip her child's fingernails as we chatted and filmed (Figure 4). These observations illustrate how backpack journalism redefines the nature of source-journalist relationship. In addition, my experience in disaster zones confirms the social constructionism theories and that because I share similar demographic qualities with my subjects, and being a Filipino myself, I felt welcomed and was given preferential access to their community (Thomson \& Greenwood, 2016). I argue that these variables complemented the natural capacity of backpack reporters to practice humanistic journalism, combining emotion and context in reporting and getting to know the subject of the story deeper (see Pantti, Wahl-Jorgensen \& Cottle, 2012; Tumber \& Prentoulis, 2003). As Ward (2010) states:

\begin{abstract}
A journalism of disasters is not a journalism of Olympian detachment. It is not a journalism fixated on stimulating the emotions of audiences. It is a humanistic journalism that combines reason and emotion. Humanistic journalists bring empathy to bear on the victims of tragedy - an empathy informed by facts and critical analysis.
\end{abstract}

In addition, being a solo journalist allows the collection of personal anecdotes which I gathered through casual conversations with typhoon survivors. In Guian town, a casual conversation with the housekeeper of the pension house where I stayed turned out to be a compelling anecdote of survival. He recounted that his family tied themselves together using extension wires so that their bodies could easily be recovered by their relatives. In a very casual but poignant interview, he also revealed the struggle of being isolated and powerless during the disaster. 'We first ate coconut, then bananas. Then we saw some chickens, pigs and cows that were washed in by the floods; we butchered and cooked them right away so we can have food,' my interviewee said in Filipino. On my first day in Guian, I also took photos and videos of Catholics celebrating a mass outside their devastated church, walked around the vicinity and took shots of the recovery like a typical traveller. These experiences verify my earlier argument that backpack journalism is an effective alternative to capture the community's typical way of life, the people's natural character and unfiltered emotions. While mainstream journalists take advantage of humanistic storytelling as well, my analysis shows that there are moments of spontaneity and authenticity that could be captured easily by a backpack journalist. 
In summary, disaster reporting, whether using conventional or convergent technologies and filed by 'one-man-band' or a production crew, follow the same principles of solid journalism. Both practices observe same news values and typical strategies of information gathering and audience engagement. However, significant differences arise in terms of production routines and legwork, access to resources, and most importantly a redefined relationship between the source and the reporter.

\section{Conclusions}

This article acknowledges the notion that multitasking news workers are as old as journalism itself. As emphasised by Schudson (1978, p. 65): 'Early newspapers had been one-man-bands, one man acted as printer, advertising agent, editor, and reporter.' Perhaps, it is safe to claim that the demarcation of skills, given the affordances of new media, will remain immaterial as new technologies alter old methodologies of reporting. The case study presented here examines disaster reporting as unexpected but routine function of journalism and shows how a differing practice of solo reporting adds valuable new elements to storytelling. It uses the idea of the 'one-man band' to illustrate the relationship between technology and reporting in disaster zones. Although backpack newsgathering means less newsroom collaboration, technology-focused news gathering, susceptible to technical issues (Avilés et al., 2004; Bock, 2012) and potentially unsustainable, it still offered the advantage of collecting more natural and personal narratives from typhoon survivors and more importantly allowed the exercise of humanistic storytelling. The emphasis on human condition, the personal anecdotes, and first-person reporting are some of the qualities of humanistic reporting highlighted in this article (Killenberg, 2008, p. 18). In other words, with sufficient preparation and training, solo journalists are able to pursue areas off the 'beaten track' or beyond the reach of a news crew and collect stories that emerge out of their natural immersion in disaster zones.

Not only information-gathering routines are changing alongside new technologies but also online journalism, a sector exposed to a climate of constant story innovation and redevelopment (Ureta \& Fernandez, 2017). New media afforded journalists with the capacity to exercise new styles of reporting such as converting complex disaster data into visual journalism, even though it is often outside their skillset. Although many news outlets prefer paid software in the creation of interactive content, I assert that free and open-source applications are excellent alternatives. By having a variety and combination of formats, digital audiences could now feel the story through still and moving images, understand deeply the story through text, and gain context through data visualisation. These changes are liberating many traditional journalists who previously practised medium-specific storytelling. 
Indeed, the lure of hybridising reporters is high in this information age (Sànchez Marín, Micó Sanz, \& Justel Vázquez, 2018) and perhaps practical due to disrupted model and economic challenges facing journalism (Phillips, 2015). Despite dissidence among news workers feeling negatively about working solo in the field, news managers can negotiate the practice when there is ample training given and when there is full acknowledgement of its limitations as a practice (Sànchez Marín et al., 2018). Since backpack reporting requires a higher level of judgment and technical and editorial skills compared to working with a production crew, I highly suggest returning to the 'job shadowing' approach when conducting multiskill training, wherein novice and experienced journalists are paired up for a specific field coverage. The 'shadow journalist' acquires tacit knowledge through participant observation while the shadowed one benefits from the opportunity to review the efficacy of his or her routine.

Converged journalism is developing evidently faster than imagined even a decade ago. The innovations in news production, from fieldwork to storytelling and even to the point of distribution, have tremendously altered both the job description and the products of new media journalists. While the reason to deploy backpack journalists to disaster zones appears to be more economic rather than strategic, it might be best for news managers to consider multiskilling as desirable but not mandatory criterion to retain news workers. It is true that the skillset of journalists must be upgraded to keep pace with emerging technologies but content is still the king and should be treated as a priority in journalism training.

\section{References}

Alexander, D. (1993). Natural disasters. New York, NY: Chapman \& Hall.

Avilés, J. A. G., León, B., Sanders, K., \& Harrison, J. (2004). Journalists at digital television newsrooms in Britain and Spain: Workflow and multi-skilling in a competitive environment. Journalism Studies, 5(1), 87-100. doi: 10.1080/1461670032000174765

Bennett, R., \& Daniel, M. (2002). Media reporting of third world disasters: The journalist's perspective. Disaster Prevention and Management: An International Journal, 11(1), 33-42. doi: 10.1108/09653560210421682

Bhuiyan, S. (2009). Strategies for developing media managers for convergence: An analysis of perspectives from management theory and practice for managers of converged newsrooms. Pranjana: The Journal of Management Awareness, 12(2), 1-15. Bock, M. A. (2012). Video journalism: Beyond the one-man-band. New York, NY: Peter Lang.

Boczkowski, P. J. (2004). The processes of adopting multimedia and interactivity in three online newsrooms. Journal of Communication, 54(2), 197-213. doi: 10.1111/j.14602466.2004.tb02624.x

Boczkowski, P. J. (2004a). Digitizing the news innovation in online newspapers. Cambridge, MA; London: MIT Press.

Boczkowski, P. J., \& Ferris, J. A. (2005). Multiple media, convergent processes, and divergent products: Organizational innovation in digital media production at a European firm. The ANNALS of the American Academy of Political and Social Science, 
597(1), 32-47. DOI: 10.1177/0002716204270067

Colon, A. (2000, May/June). The multimedia newsroom. Columbia Journalism Review, $39: 1,25-27$.

Cottle, S. (2012). Mediatized disasters in the global age: On the ritualization of catastrophe. In J. Alexander, R. Jacobs, \& P. Smith (Eds.), Oxford handbook of cultural sociology (pp. 259-283). Oxford, UK: Oxford University Press.

Creech, B. (2017). A newsmaker's tool: The $35 \mathrm{~mm}$ camera and journalism's material epistemology. Journalism, 18(9), 1125-1141. doi: 10.1177/1464884916657507

Dailey, L., Demo, L., \& Spillman, M. (2005). The convergence continuum: A model for studying collaboration between media newsrooms. Atlantic Journal of Communication, 13(3), 150-168. doi: 10.1207/s15456889ajc1303_2

Deuze, M. (2004). What is multimedia journalism? Journalism Studies, 5(2), 139-152. DOI: $10.1080 / 1461670042000211131$

Deuze, M. (2007). Media work, Cambridge, UK; Malden, MA: Polity.

Deuze, M. (2008). Understanding journalism as newswork: How it changes, and how it remains the same. Westminster Papers in Communication \& Culture, 5(2), 4-23. Retrieved from https://www.westminster.ac.uk/_data/assets/pdf_file/ 0006/20022/002WPCC-Vol5-No2-Mark_Deuze.pdf. Accessed August 7, 2014

Domingo, D. S., Aguado Terrón, J.M., Cabrera, M., Edo Bolós, C., Masip, P., Meso A., ... Giménez, E. (2011). Four dimensions of journalistic convergence: A preliminary approach to current media trends at Spain. Paper presented at the 8th International Symposium of Online Journalism. University of Texas, Austin. doi: 2011-11-22T12:10:57Z

Duhe, S. F., Mortimer, M. M., \& Chow, S. S. (2004). Convergence in North American TV newsrooms: A nationwide look. Convergence: The International Journal of Research into New Media Technologies, 10(2), 81-104. doi: 10.1177/135485650401000206

Dupagne, M., \& Garrison, B. (2006). The meaning and influence of convergence. Journalism Studies, 7(2), 237-255. doi: 10.1080/14616700500533569

Erdal, I. J. (2009). Cross-media (Re)production cultures. Convergence: The International Journal of Research into New Media Technologies, 15(2), 215-231. doi: $10.1177 / 1354856508105231$

Erdal, I. J. (2009). Repurposing of content in multi-platform news production. Journalism Practice, 3(2), 178-195, doi: 10.1080/17512780802681223

Gage, R. (2006, Winter). Navigating the road to convergence: 'Being small and a familyowned company are attributes that have helped us to become a multimedia news organization'. Nieman Reports 60(4),19-22. Retrieved from http://niemanreports. org/articles/navigating-the-road-to-convergence/

Google Maps Engine API. (2014) https://developers.google.com/maps- engine/documentation/start. Accessed June 24, 2014

Gordon, R. (2003). The meanings and implications of convergence. In K. Kawamoto (Ed.), Digital journalism: Emerging media and the changing horizons of journalism, (pp. 57-73). Lanham, MD: Rowman \& Littlefield.

Hemmingway, E. (2005). PDP, the news production network and the transformation of news. Convergence: The International Journal of Research into New Media Technologies, 11(3), 8-27. doi: 10.1177/135485650501100302

Hemmingway, E. (2008). Into the newsroom: Exploring the digital production of regional television news. London: Routledge.

Huang, E., Rademakers, L., Fayemiwo, M. A., \& Dunlap, L. (2004). Converged journalism and quality: A case study of The Tampa Tribune news stories. Convergence: The International Journal of Research into New Media Technologies, 10(4), 73-91. 
doi: $10.1177 / 135485650401000407$

Huang E., Davidson K., Shreve S., Davis T., Bettendorf, E., \& Nair, A. (2006). Facing the challenges of convergence: Media professionals' concerns of working across media platforms. Convergence, 12(1), 83-98. doi: 10.1177/1354856506061557

Infotendencias Group. (2012). Media Convergence. In E. Siapera \& A. Veglis (Eds.), The handbook of global online journalism (pp. 19-38). Malden, MA: Wiley-Blackwell.

Jenkins, H. (2006). Convergence culture: Where old and new media collide. New York, NY: New York University Press.

Kennedy, T. (2010). Whitepaper on backpack journalism. Washington, DC: American University School of Communication. Retrieved from www.american.edu/loader. cfm?csModule $=$ security/getfile \&pageid $=1713568$

Killenberg, G. M. (2008). Public affairs reporting now: News of, by and for the people. Burlington, MA: Focal Press.

Klinenberg, E. (2005). Convergence: News production in a digital age. The ANNALS of the American Academy of Political and Social Science, 597(1), 48-64. doi: $10.1177 / 0002716204270346$

Kolodzy, J. (2006). Convergence journalism: Writing and reporting across the news media. Lanham, MD.: Rowman \& Littlefield.

Kolodzy, J., Grant, A. E., De Mars, T. R., \& Wilkinson, J. S. (2014). The convergence years. Journalism \& Mass Communication Educator, 69(2), 197-205. doi: $10.1177 / 1077695814531718$

Kumar, P. (2011, December/January). Backpack journalism overseas. American Journalism Review, 32:4. Retrieved from ajrarchive.org/Article.asp?id=4986.

Larrondo, A., Larrañaga, J., Meso, K., \& Agirreazkuenaga, I. (2012). The convergence process in public audiovisual groups. Journalism Practice, 6(5-6), 788-797. doi:

$10.1080 / 17512786.2012 .667282$

Lawson-Borders, G. (2006). Media organisations and convergence: Case studies of media convergence pioneers. New Jersey NJ: Lawrence Erlbaum Associates, Inc.

Lee-Wright, P., \& Phillips, A. (2012). Doing it all in the multi-skilled universe. In P. Lee-Wright, A. Phillips \& T. Witschge (Eds.), Changing journalism (pp. 63-80). New York: Routledge.

Lewis, S. C., \& Westlund, O. (2015). Big data and journalism: Epistemology, expertise, economics, and ethics. Digital Journalism, 3(3), 447-466. DOI: 10.1080/21670811.2014.976418

Martyn, P. H. (2009). The MOJO in the third millennium. Journalism Practice, 3(2), 196-215. doi:10.1080/17512780802681264

Meyer, P. (1973). Precision journalism. Bloomington: Indiana University Pres

NDRRMC. (2013). Final report re effects of Typhoon Yolanda (Haiyan). National Disaster Risk Reduction and Management Council. Retrieved from ndrrmc.gov.ph/ attachments/article/1329/FINAL_REPORT_re_Effects_of_Typhoon_YOLANDA_ (HAIYAN)_06-09NOV2013.pdf

Örnebring, H. (2010). Technology and journalism-as-labour: Historical perspectives. Journalism, 11(1), 57-74. doi: 10.1177/1464884909350644

Pantti, M. (2010). The value of emotion: An examination of television journalists' notions on emotionality. European Journal of Communication, 25(2), 168-181. doi: $10.1177 / 0267323110363653$

Pantti, M., Wahl-Jorgensen, K., \& Cottle, S. (2012). Disasters and the media. New York, NY: Peter Lang.

Pavlik, J. (2000). The impact of technology on journalism. Journalism Studies, 1(2), 229-237. doi: 10.1080/14616700050028226 
Phillips, A. (2015). Journalism in context. Practice and theory for the digital age. Abingdon, NY: Routledge.

Pool, I. d. S. (1983). Technologies of Freedom. Cambridge, MA: Belknap Press of Harvard University Press.

Quandt, T., \& Singer, J. (2009). Convergence and cross-platform content production. In T. Hanitzsch \& J. Wahl-Jorgensen (Eds.), The handbook of journalism studies (pp.130144). New York: Routledge.

Quinn, S. (2004). An intersection of ideals: Journalism, profits, technology and convergence. Convergence: The International Journal of Research into New Media Technologies, 10(4), 109-123. doi: 10.1177/135485650401000409

Quinn, S. (2005a). What is convergence and how will it affect my life? In S. Quinn \& V. Flak (Eds.), Convergent journalism: An introduction (pp. 3-20). Boston, MA: Elsevier.

Quinn, S. (2005). Convergent journalism: The fundamentals of multimedia reporting. New York, NY: P. Lang.

Reich, Z. (2011). Comparing reporters' work across print, radio, and online: Converged origination, diverged packaging. Journalism \& Mass Communication Quarterly, 88(2), 285-300. doi: 10.1177/107769901108800204

Robinson, S. (2011). Convergence crises: News work and news space in the digitally transforming newsroom. Journal of Communication, 6(61), 1122-1141. doi: 10.1111/j.1460-2466.2011.01603.x

Sànchez Marín, G., Micó Sanz, J. L., \& Justel Vázquez, S. (2018). Journalistic MultiSkilling in the News Agencies AFP, EFE, ANSA, and ACN. Tripodos, (41), 157-172. Retrieved from www.tripodos.com/index.php/Facultat_Comunicacio Blanquerna/ article/view/440

Schudson, M. (1978). Discovering the news: A social history of American newspapers. New York: Basic Books.

Silverstone, R. (1995). Convergence is a dangerous word. Convergence: The Journal of Research into New Media Technologies, 1(1), 11-13. doi: 10.1177/135485659500100102

Singer, J. B. (2004). Strange bedfellows? The diffusion of convergence in four news organizations. Journalism Studies, 5(1), 3-18. doi: 10.1080/1461670032000174701

Smith, S. (2011). Going solo: Doing video journalism in the 21st century. Columbia, MO.: University of Missouri Press.

Stevens, J. (2002). Backpack journalism is here to stay. Online Journalism Review, 2. Retrieved from www.ojr.org/ojr/workplace/1017771575

Stewart, M., \& Hodgkinson, P. (1988). Disaster and the media. Disaster Management $1(2), 8-18$.

Strong, C. R., \& Zafra, N. (2016). Natural disaster strategic communication: Drone, data and backpack journalism trends. PRism Online PR Journal, 13(1), 1-16. Retrieved from www.prismjournal.org/fileadmin/13_1/Strong_Zafra_Natural_Disaster_Strategic_Communication.pdf

Thomson, T. J., \& Greenwood, K. (2017). Beyond Framing: Influences of subject-photographer interactions on visual journalism. Journalism Practice, 11(5), 625-644. doi: 10.1080/17512786.2016.1152908

Timeline JS overview. (2014). http://timeline.knightlab.com/. Accessed June 24, 2014

Tompkins, A. (2012). Aim for the heart: Write, shoot, report and produce for tv and multimedia, Washington, DC: CQ Press.

Tuchman, G. (1973). Making news by doing work: Routinizing the unexpected. American Journal of Sociology, 79(1), 110-131. Retrieved from www.jstor.org/stable/2776714

Tumber, H., \& Prentoulis, M. (2003). Journalists under fire: Subcultures, objectivity 
and emotional literacy. In D. Thussu and D. Freedman (Eds.), War and the media: Reporting Conflict 24/7 (pp. 215-230). London: Sage.

UNOCHA (2013). Typhoon Haiyan (Yolanda) strategic response plan: The Philippines. Retrieved from www.unocha.org/sites/dms/CAP/SRP_2013-2014_Philippines_Typhoon_Haiyan.pdf

Ureta, A. $\bar{L} .$, \& Fernández, S. P. (2017). Keeping pace with journalism training in the age of social media and convergence: How worthwhile is it to teach online skills? Journalism. doi: 10.1177/1464884917743174.

Van Leuven, S., \& Joye, S. (2014). Civil society organizations at the gates? A gatekeeping study of news making efforts by NGOs and government institutions. The International Journal of Press/Politics, 19(2), 160-180. doi: 10.1177/1940161213514615

Wallace, S. (2009). Watchdog or witness? The emerging forms and practices of videojournalism. Journalism, 10(5), 684-701. doi: 10.1177/1464884909106539

Wallace, S. (2013). The complexities of convergence: Multiskilled journalists working in $\mathrm{BBC}$ regional multimedia newsrooms. International Communication Gazette, 75(1), 99-117. doi: 10.1177/1748048512461764

Ward, S.J.A. (2010). Emotion in reporting: use and abuse. Retrieved from ethics.journalism.wisc.edu/2010/08/23/emotion-in-reporting/

Wesley, A. (2013, Spring). Today's visual journalist. Quill \& Scroll, 87(2), 7.

Zelizer, B., \& Allan, S. (2010). Keywords in news and journalism studies. Berkshire, England: Open University Press.

Zhang, S. I. (2012). The newsroom of the future. Journalism Practice, 6(5-6), 776-787. doi: $10.1080 / 17512786.2012 .667281$

\section{Acknowledgement}

This research was conducted as part of the author's Master of Journalism project at Massey University in Wellington. The author acknowledges the support and supervision of Dr Catherine Strong during the conduct of this research.

Norman Zafra is a Filipino journalist-documentary maker and currently a doctoral candidate in media and communication at the University of Auckland. He has directed, produced and written a number of documentaries and investigative reports for award-winning Philippine television programmes such as Reporter's Notebook and I-Witness. Norman won the Bruce Jesson Emerging Journalism Award in 2015 for his reporting of the Philippine reconstruction after Typhoon Haiyan disaster.

nzafra@aucklanduni.ac.nz 